\title{
Narrativas do movimento homossexual brasileiro sobre a saúde de gays e lésbicas
}

\author{
Narratives of the Brazilian homosexual movement on the health \\ of gays and lesbians
}

Romeu Gomes (https://orcid.org/0000-0003-3100-8091) ${ }^{1}$

\footnotetext{
${ }^{1}$ Instituto Fernandes Figueira, Fundação Oswaldo Cruz. Av. Rui Barbosa 716, Flamengo. 22250-020 Rio de Janeiro RJ Brasil.

romeugo@gmail.com
}

\begin{abstract}
This study analyzes narratives of health produced by representatives of gay and lesbian groups. The analysis seeks to contribute to a shift from the pathologization of non-heteronormative sexuality towards ensuring comprehensive gay and lesbian health care that takes into account the specific needs of these groups beyond HIV/AIDS. We conducted a qualitative study using narrative inquiry and drawing on previous narrative studies analyzing social movements. The results highlight collective homosexual identities and the plurality of gay and lesbian health. It is concluded that the narratives shift between the association between AIDS and homosexuality and the demarcation of differences between gay and lesbian health, leading to new demands that make these groups protagonists or supporting actors in health promotion.
\end{abstract}

Key words Gays, Lesbians, Health, Homosexual movement, Narratives
Resumo Objetivou-se analisar narrativas de representantes de grupos gays e de lésbicas sobre a saúde. Com tal análise, pretende-se contribuir para o deslocamento da associação doença/gays e lésbicas para a dimensão da atenção integral à saúde, equilibrando o tema HIV/AIDS e a emergência de necessidades de saúde desses atores. A abordagem deste estudo é caracterizada como de natureza qualitativa, utilizando o método de narrativas, com perspectiva hermenêutica e referenciais de estudos que utilizam narrativas na análise de movimentos sociais. Entre os resultados, destacam-se identidades coletivas e emergem a pluralidade de ações e necessidades de saúde voltadas para gays e lésbicas. Concluiu-se que as narrativas se deslocam da associação AIDS/homossexualidade, passando pela demarcação das diferenças de necessidades de saúde entre gays e lésbicas, chegando a demandas que colocam os grupos como protagonistas ou coadjuvantes nas ações de saúde. Palavras-chave Gays, Lésbicas, Saúde, Movimento homossexual, Narrativas 


\section{Introdução}

Entre os mais expressivos movimentos sociais (MS), destaca-se o movimento homossexual (MH). No Brasil, o MH tem como marco inicial a criação do grupo "Somos - Grupo de Afirmação Homossexual”, em maio de 1978, em São Paulo. Polletta e Jasper ${ }^{2}$ consideram que o $\mathrm{MH}$ não se enquadra nos movimentos convencionais para angariar concessões políticas e econômicas, mas se alinha à busca de reconhecimento para novas identidades e estilos de vida.

$\mathrm{O}$ alinhamento entre $\mathrm{MH}$ e ativismo contra a AIDS propiciou benefícios mútuos. Graças a esse ativismo, o MH tornou-se mais visível, conseguindo reunir ações e apoio financeiro de várias instituições. Por sua vez, o ativismo contra a AIDS, com avanços e limites, foi exitoso para se ancorar na mobilização do $\mathrm{MH}$ e transformar esse movimento como seu integrante ${ }^{3}$.

O MH se expandiu e passou a incluir uma série de diferentes sujeitos políticos e ficou conhecido como o movimento LBGT (lésbicas, bissexuais, gays, travestis e transexuais $)^{4}$. No entanto, neste estudo, focalizou-se gays e lésbicas.

É possível compreender aspectos gerais ou específicos do MH ou de outros MS por meio do estudo de narrativas. Partindo dessa premissa, este trabalho tem como objeto de estudo narrativas de grupos de gays e lésbicas. Nesse sentido, faz-se necessário apresentar aspectos teórico-conceituais sobre as narrativas. As narrativas podem ser vistas como uma forma convencional ancorada na transmissão cultural e são limitadas pelo nível de domínio do narrador e da reunião de seus colegas e mentores. São versões da realidade não regidas pela verificação empírica ou a exigência lógica, e sim pelas convenções ${ }^{5}$.

A narrativa se organiza em termos gerais e contínuos, tais como significado, personagem (reais ou imaginários), enredo (cronológico ou não) e ponto de vista ${ }^{6}$. Em relação a personagens, Polletta $^{7}$ observa que eles não são só humanos, mas semelhantes a humanos em suas características ou percepções. Segundo Ricouer ${ }^{8-10}$, a narrativa se encontra imbricada com a temporalidade da experiência humana, havendo fusão, no presente, entre passado e futuro, tornando o desconhecido em familiar e vice-versa, bem como se dá a relação dialética entre parte e todo temporal. Partilhando das ideias Ricouer ${ }^{8-10}$, Bruner ${ }^{11}$ observa que a sequencialidade é uma das propriedades da narrativa, pois nela são apresentados eventos e estados mentais envolvendo personagens ou atores; e sua configuração geral fornece o seu significado.
Além da temporalidade, Brunner ${ }^{11}$ leva em conta, nas narrativas, a espacialidade quando menciona que elas se referem a pessoas que agem no ambiente. Com base nessa observação, entende-se como espacialidade o local onde se constroem os significados de experiências ${ }^{12}$.

Polletta utiliza a narrativa para a análise de MS e concebe que, embora esses processos discursivos não sejam necessariamente instrumentalizados por lideranças, têm efeito tanto de fomentar a ação coletiva ${ }^{13}$ como de fornecer incentivos poderosos para a participação ${ }^{14}$. Segundo a autora, pode-se captar, nas narrativas, mudanças na esfera política sob perspectivas culturais, ampliando o foco para outras instâncias, como o reconhecimento de novos atores políticos ou uma nova perspectiva de compreender problemas que permeiam as políticas ${ }^{7}$. Internamente, os grupos podem utilizar narrativas tanto para fortalecer uma identidade coletiva, entendida como a conexão cognitiva, moral e emocional de um indivíduo com uma comunidade, como para desenvolver uma comunidade ou nação coerente ou ator coletivo ${ }^{14}$, e com isso podem transformar simultaneamente as identidades das pessoas de uma forma que motive a ação ${ }^{7}$.

Para ela, as narrativas são construídas dinamicamente a partir de uma interação com a sua audiência dentro de um contexto. Nesse sentido, o narrador apresenta o ponto de vista de uma história que pode ser modificada ou ampliada por seu interlocutor, que depois pode contar outras histórias sobre esse ponto de vista ${ }^{13}$.

Polletta observa que, ainda que as narrativas possibilitem melhor compreender a dinâmica da mobilização antes da consolidação de um movimento formalmente organizado, ativistas fazem mais do que contar histórias. Eles realizam protestos em espaços públicos, negociam com autoridades e avaliam suas táticas ${ }^{15}$.

Tendo essas considerações iniciais como base, objetivou-se analisar narrativas de representantes de grupos de gays e lésbicas, visando identificar e discutir elementos estruturais dessas narrativas (como cenários, enredos e personagens) relacionados à construção de agendas de saúde desses grupos.

Segundo revisão da literatura ${ }^{3}$ realizada em 2019, sabe-se que, graças às articulações entre o $\mathrm{MH}$ e os outros MS, a exemplo do feminismo, em algumas regiões do planeta, grupos de gays e lésbicas conseguiram alcançar conquistas no campo da saúde, havendo uma concentração na luta pelos direitos homossexuais e na temática HIV/ AIDS. Nessa revisão, não foi encontrada nenhuma publicação brasileira que tratasse da partici- 
pação de movimentos homossexuais em pautas específicas acerca da saúde. Trevisan ${ }^{16}$, ao historiar aspectos sobre o movimento homossexual no Brasil, observa que, na área da saúde, "é preciso ir muito além dos programas antiAIDS para elaborar políticas que atendam mais diretamente à comunidade homossexual..." (p. 58). Com base nessas considerações, o presente estudo pode preencher lacunas na literatura brasileira acerca das demandas de saúde específicas formuladas por grupos de gays e lésbicas do país. Seus resultados podem subsidiar instâncias da área da saúde, indo desde o campo das políticas, passando pela organização dos serviços, até a elaboração de linhas de cuidado voltadas para esses atores.

\section{Desenho do estudo}

Este trabalho integra uma pesquisa mais ampla, que tem como objeto agendas de saúde de grupos de gays e lésbicas, apoiada pelo Conselho Nacional de Desenvolvimento Científico e Tecnológico (CNPq) e aprovada pelo Comitê de Ética do Instituto Nacional de Saúde da Mulher, da Criança e do Adolescente Fernandes Figueira/ Fundação Oswaldo Cruz (IFF/Fiocruz).

Para tanto, pautou-se o estudo numa abordagem qualitativa que buscou investigar os sentidos que os sujeitos atribuem aos fenômenos e ao conjunto de relações em que eles se inserem ${ }^{17}$. O método aplicado foi o de estudo de narrativas. Nesse sentido, adota-se a posição de que as narrativas possuem um método próprio para o seu tratamento como objeto de estudo. Para isso, utilizou-se a proposta de Gomes e Mendonça ${ }^{18}$, que leva em conta três instâncias para o estudo das narrativas: (a) compreensão do seu contexto; (b) análise de seus aspectos estruturais (cenários, enredos e personagens); e (c) síntese interpretativa, levando em consideração o diálogo das narrativas com o referencial teórico para interpretá-las.

Para a submissão do projeto da pesquisa mais ampla ao CNPq, em 2017, consultou-se o site da Associação Brasileira de Lésbicas, Gays, Bissexuais, Travestis e Transexuais-ABGLT ${ }^{19}$. Nesse ano, foram identificados 51 grupos com as expressões homossexualidade, gays ou lésbica. Para a composição da amostra, pretendia-se sortear dois grupos por região brasileira e, em cada um deles, a princípio, realizar duas entrevistas abertas, perfazendo 20 narrativas para iniciar a análise final.

No início do trabalho de campo, em fevereiro de 2019 , fez-se contato por e-mail com alguns grupos, mas após o não recebimento de respostas às cinco primeiras mensagens e ao consultar no- vamente o site da ABGLT, observou-se que alguns grupos haviam mudado suas denominações. Isso constatado, optou-se pela técnica de amostra de universos familiares, em que pessoas conhecidas do pesquisador indicam outras a serem entrevistadas, que por sua vez indicam outras conhecidas $^{20}$. Por se tratar de grupos filiados a uma associação, a adoção dessa técnica foi bastante exitosa.

Iniciou-se o contato com um membro que tratava de questões de saúde na ABGLT. A partir dos primeiros contatos informados por ele, foi possível entrevistar representantes de grupos de dez capitais brasileiras, contemplando pelo menos dois grupos por região e dois entrevistados de cada grupo. Os critérios de inclusão para a composição dos grupos foram mantidos conforme o projeto inicial, levando em conta que os grupos escolhidos deveriam: ser filiados à $\mathrm{AB}$ GLT; ter ações voltadas para a saúde de gays e/ou lésbicas; e situar-se em dois estados diferentes de cada região brasileira.

As visitas aos grupos ocorreram no período de fevereiro de 2019 a fevereiro de 2020. Para a produção de narrativas, adaptou-se a proposta de Jovchelovitch e Bauer ${ }^{21}$, que recomenda as seguintes etapas: explicar o contexto da pesquisa e solicitar a permissão para gravar a entrevista; formular um tópico especial para a narração; não interromper a gravação até que haja indicação de que a história terminou; perguntar se o entrevistado gostaria de acrescentar mais alguma coisa; traduzir as questões da pesquisa em aspectos que surgirem nos relatos, buscando completar lacunas da história, e no final, com o gravador desligado, poderão acontecer comentários importantes para a intepretação da narrativa no seu contexto.

Neste estudo, essas etapas foram resumidas da seguinte forma: após explicar os propósitos da investigação e fornecer o Termo de Consentimento Livre e Esclarecido (TCLE), utilizou-se, como incentivo para a narrativa dos entrevistados, a seguinte questão: quais são as reivindicações do grupo que se transformaram em agendas de saúde e como foi o processo para se chegar a essas agendas? No final da narração, quando necessário, solicitavam-se esclarecimentos de dúvidas sobre algo narrado. Com o gravador desligado, às vezes ocorriam conversas livres por parte dos entrevistados, cujos aspectos principais eram anotados.

As narrativas foram analisadas utilizando-se a proposta de Gomes e Mendonça ${ }^{18}$, ampliada pelos referenciais teórico-conceituais do estudo tratados nas considerações iniciais deste trabalho. 
Para a compreensão do contexto, baseouse numa estratégia apresentada por Gomes e Mendonça, que levou em conta o referencial de Thompson $^{22}$, a de situar as narrativas nos seus lugares específicos e nos seus tempos particulares. Em outras palavras, levar em conta o espaço da atuação dos grupos e o momento em que aconteceram os relatos. As conversas livres estabelecidas com os narradores, antes e depois da narração, foram importantes para alcançar essa compreensão.

Em seguida, foram executadas as seguintes etapas: identificação de trechos dos relatos relacionados aos componentes das narrativas (cenários, personagens e enredos); descrição dos achados de cada componente das narrativas; e elaboração de síntese interpretativa, estabelecendo articulação entre componentes das narrativas, significados e princípios teóricos do estudo apresentados na introdução do presente trabalho.

\section{Resultados}

\section{Grupos e narradores}

Ao todo, teve-se acesso a 16 grupos de dez capitais de estados das cinco regiões brasileiras (Quadro 1). O grupo que tinha menor tempo de existência foi criado em 2017, e o mais antigo, em 1989. Em princípio, seriam dez grupos, entretanto, ao se chegar nas capitais, os representantes de alguns grupos convidavam outras pessoas de outros grupos para também narrarem suas experiências.

Dois grupos eram voltados exclusivamente para lésbicas, mulheres bissexuais e mulheres trans (Associação de Mulheres do Acre Revolucionárias e Coletivo Cássia). Os demais eram considerados grupos gays, mistos (gays e lésbicas) ou LGBT. Entre esses últimos, dois se destacavam com pautas específicas. Um deles (Grupo Oxumarê de Direitos Humanos de Negritude e Homossexualidade) atuava no âmbito da defesa dos direitos de negros e negras do coletivo LGBT. Outro era o RENOSP-LGBTI+ (Rede Nacional de Operadores de Segurança Pública Lésbicas, Gays, Bissexuais, Travestis, Transexuais, Intersexos e Mais), que focalizava os direitos LGBT dos servidores da segurança pública, guardas municipais, agentes de trânsito e policiais militares, civis e federais, bem como de membros da Marinha, do Exército e da Aeronáutica.

Todos os representantes dos 16 grupos, mesmo informados que o foco deste estudo eram ações de saúde de gays e lésbicas cisgêneros, em determinados momentos, reivindicavam ações voltadas para o coletivo LGBT em geral.

Nem todos os grupos tinham uma sede em espaço alugado ou próprio. Havia grupos que utilizavam espaços concedidos para a realização de suas reuniões, como sede de partido político e sala de instituições públicas, e em alguns casos a sede era o domicílio de um dos membros dos grupos.

No conjunto dos 25 narradores (Tabela 1), destacam-se as seguintes características: sexo masculino, gays, 38 anos de média de idade, cor branca e ensino superior completo. Todos eles foram tratados, neste trabalho, com nomes fictícios, seguidos por um número de 1 a 10, que se refere a códigos atribuídos às capitais.

Independentemente do grau de escolaridade, em geral os narradores eram fluentes na construção de suas narrativas, ainda que, em determinados momentos, alguns fizessem um breve silêncio por conta da emoção por revelarem aspectos doídos para si ou de outros ou para angariar a sensibilização do pesquisador ou um posicionamento (que não foi expresso) frente ao que estava sendo narrado.

Apenas dois narradores tiveram mais dificuldade para conectar as ideias num fluxo contínuo. Um deles atribuiu ao fato de estar nervoso. Ao perguntamos se ele gostaria que desligássemos o gravador, ele respondeu que não e continuou com algumas pequenas paradas e retomadas de algo já dito. $\mathrm{O}$ outro precisou de alguns pequenos estímulos para que continuasse a sua narrativa, tais como "você pode falar mais sobre isso?" $\mathrm{e}$ "tem mais alguma coisa que você queira falar sobre isso?".

\section{A percepção do contexto político brasileiro}

Assim que as visitas aos grupos se iniciaram, em fevereiro de 2019, verificou-se a percepção de que os direitos da população LGBT estavam ameaçados por conta do início do governo do presidente Jair Bolsonaro, empossado em janeiro de 2019, que, segundo Quinalha ${ }^{23}$, fez ressurgir a bandeira de valores conservadores, como a heterossexualidade compulsória. Com esse governo, foram sendo eliminadas responsabilidades relacionadas à comunidade LGBT do Ministério de Direitos Humanos, sob a alegação de o Brasil não ser um "paraíso do turismo gay"24.

A percepção do cenário político como algo negativo foi associada, em algumas narrativas, a duas ideias centrais: ameaça de retrocesso de direitos e necessidade de os movimentos se reorganizarem para o enfrentamento. 
Quadro 1. Denominações dos grupos e suas localizações.

\begin{tabular}{|l|l|l|}
\hline \multicolumn{1}{|c|}{ Grupos } & \multicolumn{1}{|c|}{ Cidades } & \multicolumn{1}{c|}{ Estado } \\
\hline 1. Grupo Arco-íris de Cidadania LGBT & Rio de Janeiro & RJ \\
2. Grupo Movimento LGBT Leões do Norte & Recife & PE \\
3. Associação da Parada do Orgulho GLBT de São Paulo & São Paulo & SP \\
4. Grupo Associação de Homossexuais do Acre & Rio Branco & AC \\
5. Associação de Mulheres do Acre Revolucionárias & Rio Branco & AC \\
6. Grupo Homossexual do Pará & Belém & PA \\
7. Grupo Oliva - Organização da Livre Identidade e Orientação Sexual do Pará & Belém & PA \\
8. RENOSP-LGBTI+ & Goiânia & GO \\
9. Grupo Oxumarê de Direitos Humanos de Negritude e Homossexualidade & Goiânia & GO \\
10. Associação Ipê Rosa LGBTI & Goiânia & GO \\
11. Associação da Parada do Orgulho GLBT de Goiás & Goiânia & GO \\
12. Grupo de Resistência Asa Branca & Fortaleza & CE \\
13. Coletivo Cássia & Curitiba & PR \\
14. Grupo Desobedeça LGBTI & Porto Alegre & RS \\
15. Conexão Diversidade & Porto Alegre & RS \\
16. Grupo Livremente & Cuiabá & MT \\
\hline
\end{tabular}

Fonte: Autor.

Tabela 1. Distribuição absoluta dos narradores.

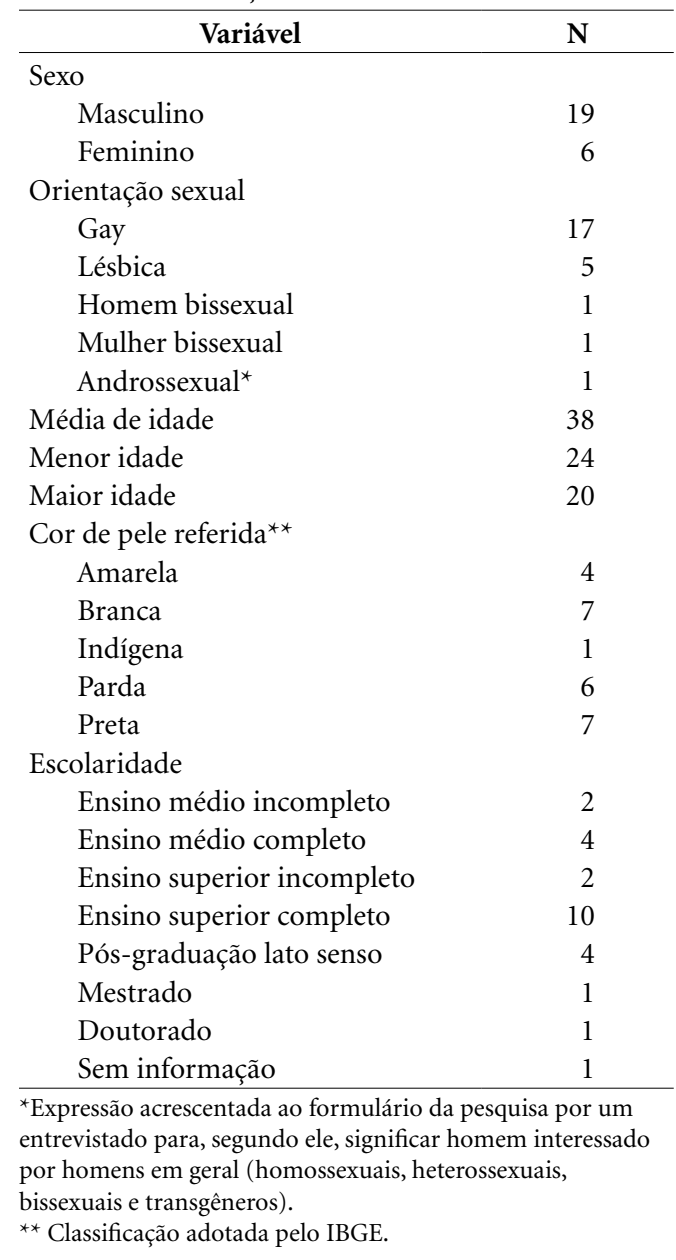

Fonte: Autor
A gente está mais focado no como combater esse governo que está vindo aí pra quebrar o movimento LGBT (Getúlio, 9). A gente está vivendo um retrocesso [...] se a gente não lutar, vai ter severas consequências (Guto, 6). [A] fala do chefe de Estado geral [...] legitima o número de violência contra nós (Lúcia, 5).

Depois de junho de 2019, foi possível perceber, em uma narrativa e em conversas livres, esperanças de mudança no cenário político pelo fato de o Supremo Tribunal Federal ${ }^{25}$ ter considerado crime os atos atentatórios a direitos fundamentais da comunidade LGBT.

Só o fato de o Supremo Tribunal Federal reconhecer que a gente está sendo vítima de um processo de violência, de exclusão, de abandono [...] é um grande avanço, mesmo no ano de um governo que é LGBTI fóbico declaradamente (Gervásio, 6)

Até janeiro de 2020, quando foram encerradas as visitas aos grupos, ainda se percebia essas preocupações e a necessidade de reorganização dos movimentos. Em alguns lugares, o encerramento do financiamento de projetos e a ausência de editais para a contração de grupos voltados para ações de saúde e de direito humanos foram mencionados. Também se detectou que os grupos, em geral, não interromperam suas ações. Isso foi possível pelos seguintes motivos: (a) em um estado, o Ministério Público forneceu espaço para as reuniões do grupo e o apoiou na defesa dos direitos LGBT com um setor específico para tratar das violações denunciadas desses direitos; (b) em determinados municípios, havia proje- 
tos com suporte financeiro para que os grupos atuassem na área da saúde e dos direitos humanos; (c) houve grupos que conseguiam arrecadar doações para desenvolver suas atividades; e (d) alguns grupos viviam unicamente à base de trabalho voluntário de seus membros ou de colaboradores.

\section{Cenários e enredos das narrativas}

Cenários e enredos, em algumas narrativas, encontram-se imbricados. Determinados narradores contavam a experiência de seus grupos, vivida em um espaço específico, outros seguiam uma ordem de relato, utilizando espaços para demarcar etapas da temporalidade do que foi vivido.

As narrativas revelam uma variedade de cenários que serve de espacialidade para ações ativistas. Entre eles, destacam-se os seguintes:

A gente vai pra espaços de sociabilidade [...] como bares, saunas, inferninhos, praças [...] e aí a gente percebe [...] que uma grande maioria não sabe onde fazer teste, não sabe onde buscar uma ajuda preventiva, um serviço de prevenção, ou se sabe relata casos de abusos, de violação de direitos (Gil, 4).

Em fevereiro quiseram tirar o CAV [Centro de Atendimento às Vitimas de Violência] por LGBT fobia, no Ministério Público [...] aí fomos na Câmara, fomos na Assembleia Legislativa, fomos na Defensoria Pública, fomos na OAB, fomos com a prefeita [...] fizemos um embate e [o CAV] voltou o funcionar (Gino, 7).

[Fazemos] atendimento domiciliar não terapêutico da pessoa com HIV para ajudar na questão da adesão ao tratamento e de repente fazer uma compra, pagar uma conta de banco porque ela não podia sair na rua, (Gonçalo, 10).

Esses cenários exemplificam tanto o lugar físico no qual as ações se desenvolveram como a dimensão da espacialidade das interrelações estabelecidas para que aspirações fossem atingidas.

Três tipos de enredos predominam nas narrativas dos representantes dos grupos acessados pela pesquisa, podendo coexistirem numa mesma narrativa. $\mathrm{O}$ primeiro deles diz respeito à história que é contada a partir das agendas que vêm sendo priorizadas ao longo da existência do grupo, sem necessariamente abandonar as já existentes. De forma ilustrativa, destaca-se o seguinte relato:

Então a gente continua trabalhando, muitos anos sobre a questão do HIV e a AIDS, mas chegamos num patamar que [...] a gente precisava ampliar o discurso [...]. Então, pulamos para advocacy na incidência política e na questão do legislativo na busca, por exemplo, na implementação de leis federais, a qual o Brasil não tem nenhuma ação realmente concreta para a população LGBT. Então [surgem] as decisões do campo legal e entendimento do Supremo Tribunal Federal, é o caso do casamento das pessoas do mesmo sexo e outras questões [...] no âmbito social, na área da saúde para travestis e transsexuais, as questões dos programas específicos da saúde do homem, o programa da população LGBT, a questão da saúde da mulher, incluindo a população de lésbicas e mulheres bissexuais (Gonçalo,10).

Esse tipo de enredo aponta a ampliação de agendas e do foco de gays e lésbicas para outros segmentos da comunidade LGBT.

O segundo tipo de enredo se caracteriza pelo predomínio da história pessoal para exemplificar o que o grupo deve apoiar ou enfrentar, bem como revelar as raízes das motivações do narrador para se tornar membro de um grupo que partilha de experiências parecidas com as suas.

Nesse caso, o narrador assume o papel de personagem em determinados momentos da narrativa. O exemplo que se segue é emblemático.

Eu não pedi para nascer gay [...] eu nasci gay. Ninguém vira [gay]. Eu sou pai, eu tenho um filho de 25 anos, na faculdade. Casei-me, fui evangélico, tudo para viver em paz com a sociedade. E hoje vi que nada valeu a pena porque vivo o mesmo medo, vivo a mesma tortura, antes eu botava o joelho no chão, orava, pedia a Deus pra morrer... hoje eu peço para viver, e eu estou sentindo que vai chegar esse retrocesso de eu voltar a pedir a morte [...] Ser gay num país desses não é fácil (Gerônimo, 5).

Esse relato ilustra a trajetória de gays mais velhos que viveram um script da heteronormatividade para serem aceitos e então, em determinado momento de suas vidas, conseguem assumir sua orientação sexual não hegemônica. Mas, no caso de Gerônimo, o assumir ser gay voltou a ser problemático. Se levarmos em conta as características socioeconômicas desse narrador, é possível levantar como hipótese que o fato de gays serem negros e pertencerem a um extrato socioeconômico mais desfavorecido pode implicar maiores dificuldades de enfrentamento das reações homofóbicas.

O terceiro tipo de enredo diz respeito à não equanimidade da atenção às lésbicas, comparando-a com a que é dada aos gays. Em alguns casos, elas são invisibilizadas.

Numa linha de tempo entre saúde dos gays $e$ saúde das lésbicas, e ainda se colocasse hoje a saú- 
de trans, a gente vai ver que a saúde gay foi lá em cima, a saúde trans despontou como um furacão e a saúde das lésbicas continuou lá embaixo, caída numa invisibilidade total (Laís, 10).

Então a gente ainda brinca dizendo que tem agosto [mês da visibilidade lésbica] e a Parada é em setembro. A gente até tem uma esticada até 29 de agosto. A Parada normalmente é segundo domingo de setembro. A gente fica nessa evidenciazinha (Leda, 9).

[...] historicamente há o predomínio dos gays no movimento Parada [...]. Agora, durante esses 23 anos que a Parada existe, a nossa atual presidente é uma lésbica (Guilherme, 8).

Essa menor atenção às lésbicas, comparada com a dada aos gays, foi mencionada por alguns representantes como algo externo e interno aos grupos.

\section{Personagens}

O entendimento de personagem, neste estudo, não se limita a pessoas ou grupos, refere-se a tudo que é personificado pelos narradores.

\section{AIDS}

Foi observado que a AIDS surge ainda associada ao medo da morte ou como algo que se pode controlar. Na prevenção ou no controle da AIDS, além do uso do preservativo, novas tecnologias despontam nas narrativas. Com isso, percebeu-se que alguns grupos perderam o investimento público para atuar contra a AIDS.

A gente vê uma epidemia [da AIDS] crescendo novamente, principalmente atingindo uma população de jovens gays (Gonçalo, 10).

Agora, dinheiro público a gente não vê [...]. Antigamente nós tínhamos um trabalho junto à Secretaria de Saúde do Estado [sobre a AIDS] e hoje não tem mais e eu vejo que esse é um problema (Gregório, 2).

Falar de AIDS é como você assinar um atestado de morte [...] se você tem câncer, todo mundo abraça e leva, caminha junto, se você tem AIDS, todo mundo se afasta como se isso fosse um contágio social (Gaspar, 1).

A PrEP [Profilaxia Pré-Exposição] te previne do HIV e o preservativo te previne da sifilis e aí você vai combinando a sua prevenção [...]. Você vai buscar a PEP [Profilaxia Pós-Exposição] se você é soropositivo e você tem um parceiro que é soronegativo [...]. As pessoas se veem mais munidas de certas tecnologias para aumentar o seu nivel de segurança e de saúde pessoal e coletiva (Gesse, 4).

\section{Saúde mental}

Em geral a saúde mental é personificada como uma das pautas mais importantes para gays, lésbicas e demais integrantes do coletivo LGBT. Ela se afigura principalmente para apoiar ou acolher gays e lésbicas que sofrem depressão e abandono por conta de assumirem sua orientação sexual. Também é vista como tendo papel importante na prevenção de suicídio que, segundo alguns narradores, vem surgindo por conta de gays, lésbicas e demais segmentos do coletivo LGBT não conseguirem lidar com o sofrimento causado pelas discriminações e não aceitação de assumirem e viverem uma orientação sexual não hegemônica. Por fim, deve ser acionada para a despatologização, que, segundo alguns narradores, no passado recente havia sido superada mas no atual cenário, em determinados segmentos ligados ao governo federal, volta a assombrar a homossexualidade como algo a ser "curado".

Se for pensar na questão da saúde mental, por exemplo, hoje a interação com os Conselhos [de psicologia] é muito interessante para, por exemplo, não tratar a homossexualidade como doença e buscar uma pseudocura (Gonçalo, 10).

Saúde mental é uma pauta superimportante [...] principalmente as lésbicas que têm uma questão de identidade de gênero que flui muito ali dentro do mundo masculino, também uma questão de não aceitação, de vergonha, de expulsão domiciliar, de abandono, que gera depressão, que gera tentativas de suicídio; esses quadros psicológicos, psiquiátricos, que levam no final ao suicídio (Letícia, 3).

Interessante observar que alguns representantes de grupos exerciam, de certa maneira, a promoção da saúde mental, ainda que de forma leiga, ao promoverem a escuta e o apoio a pessoas dentro e fora de seus grupos que se encontravam em sofrimento por conta de sua homossexualidade.

\section{O médico}

Em geral, o médico é um personagem que sintetiza questionamentos relacionados à formação de profissionais, à organização e à oferta de atendimentos da área da saúde. Somado a esses aspectos, esse personagem também é associado a preconceitos.

A gente sabe, com relação ao ginecologista, que há muitas vezes uma negligência em fazer exame Papanicolau [em lésbicas]. Outro fator é a questão da reprodução assistida [...] há uma dificuldade das lésbicas que pretendem ser assistidas dentro do SUS porque não se entende por que que elas vão querer fazer e gerar um filho (Laís, 10). 
Acho que a grande maioria dos médicos tem as presunções. Se eu sou lésbica, já presume que eu não preciso fazer exame, que eu nunca tive penetração, ou se não tive um hímen rompido e aí passa exames que talvez eu não pudesse. [Por outro lado, há uma] quantidade de meninas que disseram que eram lésbicas e o médico começou a fazer toda uma conversa de que Deus não quer isso (Leda, 10).

Eu fui pedir um encaminhamento para fazer meu exame de próstata. Aí ele disse assim: "Você está com hemorroida?" Eu disse não, eu quero fazer exame de próstata. Fiquei pensando, ele quis dizer negócio da hemorroida porque eu faço sexo anal (Gino, 7).

Eu estava com uma fístula anal. E eu percebi que ele [médico] ficou meio que sem jeito de tratar a questão, querendo que a consulta acabasse mais rápido (Gervásio, 6).

Duas narrativas se destacam por se diferenciar desses questionamentos gerais. Uma atesta aspectos positivos no atendimento médico:

O médico que me atende é muito tranquilo assim e me deixa muito tranquilo em relação ao tratamento (Gaspar, 1).

Outra narrativa apresenta uma faceta do envolvimento do médico como conivente com um esquema de internação de gays e lésbicas jovens por parte da família para que sejam "curados".

As lésbicas eram sedadas o tempo todo, amarradas, dormindo, sonolentas, pra não entenderem o que estava acontecendo. Quando acordavam pouco, a gente tentava conversar com elas, elas pediam socorro, que não eram loucas, elas estavam na psiquiatria! Só que, quando a denúncia chega, as pessoas ligam na recepção e falam que vão fazer uma visita. Aí o hospital sabia que estava errado; chamava o médico da paciente; dava alta e o pai e a mãe levavam e eu perdia de vista. A gente sofreu uma tortura, um retrocesso [...] E a gente não quer mais voltar pro armário, a gente quer só viver e ser feliz... armário nunca mais! (Gerônimo, 5).

\section{Violência}

A violência surge em várias narrativas como antagonista ao direito de viver uma sexualidade fora da hetoronormatividade. Esse personagem afigura-se com uma tríplice faceta: estrutural, física e psicológica; exercendo papéis para discriminar, estigmatizar, combater e interditar a existência das diferenças de orientações sexuais. Os narradores que tratam dela tanto falam de si como de outros participantes da comunidade LGBT de seu entorno. De acordo com eles, seus efeitos são medo, sofrimento e, em alguns casos, suicídio. Em uma das narrativas, é explicitado que a violência pode ser acirrada quando se trata de ser mulher homossexual negra.

Com esse [presidente] ficou muito mais difícil. Sofremos muito mais violência, estamos com mais medo de sair na rua, a gente não sai mais igual saía antes porque a violência está nos cercando (Gerônimo, 5).

A nossa preocupação é a violência, mas é além disso, é a discriminação, é o desrespeito, que não necessariamente vai gerar uma violência física, mas gera um estigma, uma exclusão, gera suicídio (Gilberto, 5).

Quando uma mulher preta fala, a gente cala e ouve sempre, cala e escuta, e a gente aprende muito na escuta, a violência é quase 90\% muito maior! Ela fala, "eu posso escolher, eu posso esconder que eu sou lésbica, eu posso esconder que eu sou bi, mas não posso esconder minha pele". Então é a primeira violência que elas [as lésbicas negras] sofrem (Luciana, 3).

No conjunto das situações narradas, esses depoimentos, além de ilustrativos, podem ser um prenúncio de homicídios envolvendo lésbicas, gays e outros integrantes do coletivo LGBT.

\section{A Parada}

A Parada é um personagem politicamente significativo. Sintetiza a identidade do movimento LGBT, representando o orgulho e a cultura do movimento. Ainda que possa ocorrer numa data específica, em torno dela há uma mobilização que pode ocorrer num longo período anual.

Para muitas pessoas, a Parada é só um dia, é só uma festa. Para nós, a Parada é muito mais do [que isso]. É a coroação de todas as ações, de todos os enfrentamentos, de todas as vitórias que a gente construiu durante o ano todo. Na Parada, você vai lá se colocar, se orgulhar e reivindicar mais coisas. É nesse processo de construção que a gente tem que fazer as conversações, as articulações, tanto com a iniciativa privada como com o poder público (Gilmar, 4).

A Parada de 1999, a Parada dos 100 mil participantes, foi um dos motivos para me aproximar da Parada, além da pauta de direitos humanos, era a força que a Associação passou a ter e essa força politica (Guilherme, 8).

\section{Síntese interpretativa das narrativas}

Ricoeur $^{6}$ e Bruner ${ }^{11}$ destacam, cada um a seu modo, que enredos, cenários e personagens não têm vida ou significado próprios. É na articulação ou na configuração desses componentes que se pode apreender seus significados específicos e os da narrativa em geral. 
O significado central que se desprende das narrativas em foco, implícita ou explicitamente, refere-se a uma identidade coletiva que os narradores querem comunicar. A personagem Parada é emblemática para reforçar ou criar essa identidade. Em todas as capitais visitadas, tal personagem era mencionada como um evento local ou como acontecimento que ocorria em grandes capitais. A primeira Parada brasileira, ocorrida na Avenida Paulista, na capital de São Paulo, em 1997, em seu tema "Somos muitos, estamos em todas as profissões"26, já apontava para o esboço de uma identidade coletiva. Camargos ${ }^{1}$, considerando a Parada como uma vitória simbólica sobre o medo e a paranoia da morte, observa: "se antes nos escondíamos de tudo, inclusive para morrer, pois a AIDS era o grande monstro, hoje buscamos nos mostrar para viver, pois o espírito da $\mathrm{f}(\mathrm{r})$ esta nutre a vida de esperança, sobretudo em momentos de golpe" (p. 434).

Polletta ${ }^{15}$ observa que a identidade homossexual emerge dos processos de urbanização e industrialização e que tanto se tornou alvo da repressão quanto possibilitou a criação de um ator coletivo homossexual. Ao analisar as identidades homossexuais brasileiras, $\mathrm{MacRae}^{27}$ chama atenção para o fato de o mundo homossexual ser diverso historicamente, não havendo uma adesão homogênea para a tradução dessas identidades, como ser entendido ou ser gay.

Em particular, por meio da escuta do que era narrado, o ator coletivo instituído no âmbito dos grupos ora se desdobrava em identidades específicas, como as de gay e lésbica, ora era ampliado para outras identidades que envolviam sexualidades não hegemônicas, como as de travesti e trans, mencionando o coletivo LGBT.

Em geral, nas narrativas se demarcava o ser gay e o ser lésbica ou se mencionava o coletivo LGBT, praticamente não surgia o ser homossexual. Em algumas narrativas eram mencionadas identidades invisibilizadas no coletivo LGBT, como lésbica e bissexual. No caso da necessidade de demarcar a identidade lésbica, pode ser interpretada pelo fato de lésbicas, historicamente, lutarem em duas frentes: "contra relações de dominação entre os sexos e contra a reprodução dos papéis de dominador e dominado no ambiente homossexual" (p. 48)

Uma narrativa evidenciou que a recorrência atual das discussões sobre a identidade trans poderia obscurecer outras identidades. Aqui, compreende-se que o uso recorrente do coletivo LGBT se destinava muito mais a uma audiência externa, visando assegurar o direito da diversi- dade sexual, do que aos membros internos, que procuravam sempre demarcar o lugar de uma identidade específica dentro desse coletivo.

Observou-se que a identidade sexual não hegemônica per se não era suficiente para definir a segregação que alguns/algumas narradores/as sofriam em suas comunidades. Assim, tais atores faziam questão de diferenciar "gay, negro e pobre" de "gay, branco e economicamente mais favorecido", o mesmo caso ocorria com as lésbicas. Isso pode indicar a necessidade de se desenvolver investigações acerca da interseccionalidade (que não é o foco deste estudo), que se refere à interconexão entre categorizações sociais, como raça, classe e gênero, que criam sistemas de discriminação sobrepostos e interdependentes ou desvantagen $s^{28}$.

Especificamente no que se refere à área da saúde, o significado que emerge das narrativas é o da pluralidade de ações e necessidades de saúde voltadas para gays e lésbicas.

A presença da AIDS como uma das personagens das narrativas ainda se afigura em quase todas as narrativas. Isso reflete a ideia de que historicamente o ativismo relacionado à AIDS e os movimentos de luta pelos direitos de gays e lésbicas se beneficiaram mutuamente em termos de conquistas sociais ${ }^{3}$. Embora esse personagem tenha se deslocado da ideia de sentença de morte para a de doença crônica, permanece no imaginário social a responsabilização dos comportamentos individuais por contrair a doença ${ }^{29}$. Entretanto, em algumas narrativas, essa personagem é associada à busca de novas formas de prevenção, que vão para além do uso de preservativo, a exemplo da PrEP e da PEP, envolvendo uso de medicamentos. Nas narrativas produzidas por lésbicas, a AIDS foi ofuscada por outras questões, como o câncer de mama. Na literatura internacional, observa-se que, devido às lésbicas terem ficado fora de movimentos de HIV/AIDS, o foco de questões de saúde voltadas para elas se deslocou para a conscientização sobre o maior risco de câncer de mama entre lésbicas ${ }^{3}$.

À exceção da AIDS e do câncer de mama, os demais personagens relacionados à saúde podem ser vistos como associados aos significados das identidades. Assim, a saúde mental surge como uma demanda para promover um apoio para que identidades sejam aceitas ou vivenciadas; o médico simboliza um atendimento de saúde que, em geral, não está adequadamente preparado para lidar com a sexualidade que foge do padrão heteronormativo; e a violência emerge como uma personagem que cerceia, impede, ataca e promo- 
ve o apagamento daqueles que têm uma identidade sexual não hegemônica.

Além do significado de afirmação de identidades individuais e coletivas e de pluralidade de demandas para atenção de saúde voltadas para gays e lésbicas, evidenciam-se os de agradecimento e persuasão. O agradecimento foi manifestado por alguns narradores por se sentirem valorizados pelo fato de um pesquisador sair do Rio de Janeiro para ouvi-los. Já a persuasão foi percebida porque se identificou, na escuta das histórias, o que Polletta ${ }^{13}$ denomina de apelo à emoção, em vez da razão. Nessa escuta, percebeu-se que havia, em algumas narrativas, o desejo implícito de que o pesquisador fosse porta-voz de histórias que não são ouvidas, que são desconsideradas ou até mesmo silenciadas.

\section{Considerações finais}

Os vários cenários chamaram atenção para a diversidade de espaços utilizados para viabilizar a realização das ações e indicar alvos estratégicos para que os propósitos fossem exitosos. Alguns espaços serviam para essa dupla função. A exemplo disso, um grupo utilizava a sede do Ministério Público para se reunir, bem como estabeleciam articulações com essa instituição para que os direitos do coletivo LGBT fossem assegurados.

Os enredos se afiguram como a articulação de episódios ou de trajetórias pessoais e grupais de quem vive, sobrevive e se reinventa para assegurar o direito de vivenciar identidades sexuais não hegemônicas, e surgem também para colocar em pauta temas que reforcem o respeito à diversidade sexual.

No que se refere a personagens, foi observado desde a ressignificação de alguns que já são clássicos na mobilização dos MS, voltados para a diversidade sexual, até o aparecimento de outros novos. É claro que todos os personagens foram criados para atender ao disparador que incentivou a produção de narrativas que se inseria no campo da saúde.

Pôde-se verificar que as identidades homossexuais - implícitas ou explícitas que foram expressas nas narrativas - não autorizam, com base em Polletta ${ }^{15}$, torná-las as narrativas representativas de gays e lésbicas, correndo o risco de apagar as diferenças dentro dos grupos visitados e de outros grupos em geral. Isso, ainda com base na mencionada autora, não significa que se acredite que as narrativas escutadas nesta pesquisa não se enquadrem em um estoque cultural de enredos acerca dessas identidades.

Por fim, concluiu-se que, no que diz respeito à saúde, individual ou coletiva, em geral as narrativas se deslocaram do predomínio da associação AIDS/homossexualidade, passando pela demarcação das diferenças de necessidades entre gays e lésbicas, para novas demandas que colocam os grupos não só como consumidores de bens de saúde, mas como protagonistas ou coadjuvantes na promoção desses bens.

\section{Financiamento}

O estudo foi financiado pelo Conselho Nacional de Desenvolvimento Científico e Tecnológico (CNPq), por meio de concessão de Bolsa de Produtividade. 


\section{Referências}

1. Camargos ML. O surgimento das Paradas LGBT no Brasil. In: Green JN, Quinalha R, Caetano M, Fernandes M, organizadores. História do Movimento LGBT no Brasil. São Paulo: Alameda; 2018. p. 421-434.

2. Polletta F, Jasper JM. Collective Identity and Social Movements. Annual Rev of Sociol 2001; 27:283-305.

3. Gomes R. Participação dos movimentos sociais na saúde de gays e lésbicas. Cien Saude Colet 2019; 26(6):2291-2300.

4. Facchini R, França IL. De cores e matizes: sujeitos, conexões e desafios no Movimento LGBT brasileiro Sexualidad, Salud y Sociedad. Rev Latinoamericana 2009; 3:54-81.

5. Bruner J. The Narrative Construction of Reality. Critical Inquiry 1991; 18 (1):1-21.

6. Ricouer P. The narrative function. In: Thompson JB editor. Hermeneutics and the human sciences. Cambridge: Cambridge University Press; 1998. p. 275-296.

7. Polletta F, Gardner GG. Narrative and Social movements. In: Della Porta D, Diani M. The Oxford Handbook of Social Movements. Oxford: Oxford Press; 2015. p.535-548.

8. Ricouer P. Tempo e narrativa. Campinas: Papirus; 1994. Tomo I.

9. Ricouer P. Arquitectura y narratividad. Dossier. Edicions UPC; 2002. p. 9-29. [acessado 2020 Set 22]. Disponível em: https://upcommons.upc.edu/bitstream/ handle/2117/120787/9788498800104-03.pdf?sequen$\mathrm{ce}=1$ \&isAllowed $=\mathrm{y}$.

10. Ricouer P. Entre tempo e narrativa: concordância/discordância. Kriterion 2012; 125:299-310.

11. Bruner J. Actos de significados. Lisboa: Edições 70; 2008.

12. Gomes R, Lima VV. Narrativas sobre processos educacionais na saúde. Cien Saude Colet 2019; 24(12):46874697.

13. Polletta F. It was like a fever. Storytelling in protest and politics. Chicago: University of Chicago Press; 2006.

14. Polletta F. Contending Stories: narratives in social movements. Qualitative Sociology 1998; 21(4):419-446.

15. Polletta F. "It Was like a Fever ..." Narrative and Identity in Social Protest. Social Problems 1998; (45)2:137159.

16. Trevisan JS. Homocultura \& política homossexual no Brasil: do passado ao porvir. In: Costa H, Bento B, Garcia W, Inácio E, Peres WS, organizadores. Retratos do Brasil homossexual: fronteiras, subjetividades e desejos. São Paulo: Editora da Universidade de São Paulo, Imprensa Oficial; 2010. p. 49-59.

17. Minayo MCS. O desafio do conhecimento: pesquisa qualitativa em saúde. São Paulo: Hucitec; 2004.

18. Gomes R, Mendonça EA. A representação e a experiência da doença: princípio para a pesquisa qualitativa em saúde. In: Minayo MCS, Deslandes SF, organizadores. Caminhos do pensamento: epistemologia e método. Rio de Janeiro: Fiocruz; 2002. p. 109-32.

19. Associação Brasileira de Lésbicas, Gays, Bissexuais, Travestis e Transexuais (ABGLT). [acessado 2017 Mai 16]. Disponível em: http://abgltbrasil.blogspot.com. br/p/afiliadas.html
20. Vaitsman J. Flexíveis e plurais: identidade, casamento e família em circunstâncias pós-modernas. Rio de Janeiro: Editora Rocco; 1994.

21. Jovchelovitch S, Bauer MW. Entrevista narrativa. In. Bauer MW, Gaskell G, organizadores. Pesquisa qualitativa com texto, imagem e som. Um manual prático. Petrópolis, Rio de Janeiro: Vozes; 2002. p. 90-113.

22. Thompson JB. Ideologia e cultura moderna: teoria social crítica na era dos meios de comunicação de massa. Petrópolis: Vozes; 1998.

23. Quinalha R. Os direitos LGBT sob o governo Bolsonaro. Le monde diplomatique Brasil 2019; Edição 143. [acessado 2020 Jun 3]. Disponível em: https://diplomatique.org.br/os-direitos-lgbt-sob-o-governo-bolsonaro/

24. El País. Brasil criminaliza homofobia e reforça queda de braço com conservadorismo. 14 jun 2019. [acessado 2020 Jun 3]. Disponível em: https://brasil.elpais.com/ brasil/2019/06/14/actualidad/1560496365_764572. html

25. STF. STF enquadra homofobia e transfobia como crimes de racismo ao reconhecer omissão legislativa. 13 jun 2019. [acessado 2020 Jun 12]. Disponível em: https://portal.stf.jus.br/noticias/verNoticiaDetalhe. asp?idConteudo $=414010$

26. Facchini R. Sopa de letrinhas? Movimento homossexual e produção de identidades coletivas nos anos 1990. Rio de Janeiro: Garamond; 2005.

27. McRae E. Identidades homossexuais e movimentos sociais urbanos no Brasil da "Abertura". In: Green JN, Quinalha R, Caetano M, Fernandes M, organizadores. História do Movimento LGBT no Brasil. São Paulo: Alameda; 2018. p. 39-62.

28. Perlman M. The origin of the term intersectionality [internet]. Columbia Journalism Review 2018. [cited 2020 Dec 26]. Available from: https://www. cjr.org/ language_corner/intersectionality.php.

29. Silva AFC, Cueto M. HIV/AIDS, os estigmas e a história. Hist Cienc Saude Manguinhos 2018; 25(2):311314.

Artigo apresentado em 15/01/2021

Aprovado em 08/03/2021

Versão final apresentada em 10/03/2021

Editores-chefes: Maria Cecília de Souza Minayo, Antônio Augusto Moura da Silva 
